\title{
Article \\ Deformation Behavior of Internal Porosity in Continuous Casting Wide-Thick Slab during Heavy Reduction
}

\author{
Chenhui $\mathrm{Wu}^{1,2}$, Cheng $\mathrm{Ji}^{1,2, *}$ and Miaoyong $\mathrm{Zhu}^{1,2}$ \\ 1 Key Laboratory for Ecological Metallurgy of Multimetallic Ores (Ministry of Education), Shenyang 110819, \\ China; wch_neu@126.com (C.W.); myzhu@mail.neu.edu.cn (M.Z.) \\ 2 School of Metallurgy, Northeastern University, 3-11 Wenhua Road, Shenyang 110819, China \\ * Correspondence: jic@smm.neu.edu.cn; Tel.: +86-138-9881-2341
}

Received: 20 December 2018; Accepted: 23 January 2019; Published: 25 January 2019

\begin{abstract}
Heavy reduction (HR) is a novel technology that could effectively improve the internal porosities and other internal quality problems in continuously cast steel, during which a large reduction deformation is implemented at and after the strand solidification end. In the present paper, non-uniform solidification of the wide-thick slab was calculated with a two-dimensional (2D) heat transfer model. Based on the predicted temperature distribution at the solidification end of the casting strand, a three-dimensional (3D) thermal-mechanical coupled model was developed for investigating the deformation behavior of the internal porosities in wide-thick slab during HR. An Arrhenius-type constitutive model for the studied steel grade was derived based on the measured true stress-strain with single-pass thermosimulation compression experiments and applied to the 3D thermal-mechanical coupled model for improving the calculation accuracy. With the developed 3D thermal-mechanical coupled model, deformation behavior of the two artificial porosities located at the slab center of $1 / 2$ width and $1 / 8$ width during HR was investigated under different condition of HR deformation, HR start position, and HR reduction mode. Based on the calculated porosity closure degree $\left(\eta_{\mathrm{s}}\right)$ and the corresponding equivalent strain $\left(\varepsilon_{\mathrm{eq}}\right)$ under different HR conditions, a prediction model that describes the quantitative relationship between $\eta_{\mathrm{s}}$ and $\varepsilon_{\mathrm{eq}}$ was derived for directly and accurately evaluating the process effect of HR on improving the internal porosities in wide-thick slab.
\end{abstract}

Keywords: continuous casting; wide-thick slab; non-uniform solidification; heavy reduction; porosity; deformation

\section{Introduction}

Due to solidification shrinkage and gas entrapment, internal porosity often occurs in casting steel. As one kind of the common internal defects, it seriously influences the mechanical properties of the final products, for example, decreasing the fatigue life and the yield strength, and should be eliminated in the subsequent rolling or forging process.

To provide theoretical guide for process design of rolling or forging, many investigations were carried out by previous researchers to clarify the closure mechanism of internal porosity in metal materials during the forging or rolling process. To quantitatively evaluate the porosity closure during forging process, Tanaka et al. [1] proposed the hydrostatic integration parameter, which was widely adopted as an indicator of the porosity closure degree by subsequent researchers [2-5]. In addition to the hydrostatic integration parameter, many other researchers [6-9] also adopted effective strain as the indicator of porosity closure degree during hot working process, and different threshold values mboxciteB7-metals-421132,B8-metals-421132,B9-metals-421132 of effective strain for eliminating the 
internal porosity were reported. Recently, a void aspect ratio evaluation index, defined as a function of stress deviator, effective strain, and effective stress, was proposed by Chen et al. [10], which could give an accurate description of the porosity evolution during forging process. After carrying out full-scale hot-rolling experiments, Ståhlberg et al. [11] concluded that temperature gradient between the lower temperature on workpiece surface and the higher temperature in its internal region, as obtained by water cooling, was advantageous for the elimination of internal porosity with a relatively small rolling reduction. The effect of temperature gradient was further discussed in the later studies of forging $[4,12]$ or rolling $[3,13,14]$ with numerical or experimental methods, and all of these investigations confirmed the promotion effect of temperature gradient on the porosity closure. During forging process, die shape is another critical process parameter that influences the process effect on eliminating the internal porosities in workpiece, and in order to design an optimum die geometry, some studies were conducted by previous researchers to investigate the effect of die shapes on porosity closure during open die forging [6,15,16], upset process [4], and hot radial forging [17], et al.

Internal porosities in casting steel usually could be eliminated by rolling or forging process. However, due to the increased solidification time for casting steel with a large section size, its internal porosities become more serious with the presence of coarser cast structure $[4,18]$. Under condition of large components that were produced by rolling or forging with a relatively low compression ratio [11,19-21], the serious internal porosities in large section size casting steel could not be easily eliminated, which seriously influences the mechanical properties of the final products. Meanwhile, as one of the main counter measures of the internal porosities, the traditional mechanical soft reduction (SR) [22,23] was proved to be insufficient on significantly improving the serious internal porosities in the casting steel with a large section size. In order to improve the serious internal defects in continuous casting steel significantly, some earlier researchers [24-27] proposed heavy reduction (HR) technology. By implementing a large reduction deformation around the strand solidification end, the internal quality of continuous casting steel could be significantly improved by HR, which effectively contributes to the complete elimination of internal porosity in the subsequent rolling or forging process.

As an effective counter measure of internal defects in continuous casting steel, HR has attracted more and more researchers' attention with the rapidly increased demand for large components in the large equipment manufacturing industry in recent years. Some theoretical and experimental investigations were carried out recently for studying the improving effect of HR on porosity and other internal defects in continuous casting bloom [28,29], billet [30], or slab [19-21], and some new HR technologies were then proposed and applied. By establishing a three-dimensional (3D) thermal-mechanical coupled model, the present authors [28] studied the deformation behavior of continuous casting bloom during HR and developed the two-stage sequential heavy reduction technology. Industrial trials indicated that the homogeneity and compactness of the continuous casting bloom could be obviously improved after the application of two-stage sequential heavy reduction technology. Based on numerical simulation results, two kinds of new HR technologies, named as START and HRPISP, were respectively proposed by $\mathrm{Xu}$ et al. [19] and Zhao et al. [20,21] for simultaneously improving the internal porosity and macro-segregation in continuous casting wide-thick slab, and the effectiveness of START was proved by experimental results in plant.

To provide theoretical basis for the development of the HR process and thus improve the internal porosities in wide-thick slab more effectively, the porosity deformation behavior during HR in the wide-thick slab continuous casting process was systematically investigated mainly by the numerical simulation method in the present work. A two-dimensional (2D) heat transfer model was established to calculate the non-uniform solidification process of the wide-thick slab. Based on the predicted heat transfer results by the 2D heat transfer model and the derived constitutive model for the studied steel grade during HR, a 3D thermal-mechanical coupled model, containing two artificial spheroidal porosities, respectively, located the slab center of $1 / 8$ width $\left(\mathrm{P}_{1 / 8}\right)$ and $1 / 2$ width $\left(\mathrm{P}_{1 / 2}\right)$, was established. With this $3 \mathrm{D}$ thermal-mechanical coupled model, the deformation behavior of $\mathrm{P}_{1 / 8}$ and $\mathrm{P}_{1 / 2}$ during $\mathrm{HR}$ was numerically investigated under different HR conditions, including the HR deformation, HR start 
position, and HR mode. Based on the predicted porosity deformation results under different HR conditions and the corresponding equivalent strain $\left(\varepsilon_{\mathrm{eq}}\right)$, a prediction model for the porosity closure behavior was derived to describe the quantitative relationship between the porosity closure degree $\left(\eta_{\mathrm{s}}\right)$ and $\varepsilon_{\mathrm{eq}}$.

\section{Finite Element Model}

\subsection{D Heat Transfer Model}

During HR, the deformation behavior of the casting strand is closely related to its temperature distribution. In order to improve the calculation efficiency, a 2D heat-transfer model, as shown in Figure 1, was firstly developed with the commercial finite element software MSC.Marc (2013.0.0, MSC Software Corporation, Newport Beach, CA, USA) based on the practical casting conditions in Table 1 and some simplified conditions [31]. Heat transfer analysis was then carried out with this model, which determined the strand solidification end and the corresponding initial temperature field for the subsequent 3D thermal-mechanical coupled model in Section 2.2. Due to the symmetry of heat transfer behavior of the casting strand along its width direction, half of the wide-thick slab transverse section, as shown in Figure 1, was taken as the calculation domain. Four-nodes quadrilateral elements with a side length of $5 \mathrm{~mm}$ were applied to uniformly mesh the calculation domain, and the final $2 \mathrm{D}$ heat transfer model contains 11,200 elements and 11,457 nodes. Automatic time step with $0.1 \mathrm{~s}$ and $1 \mathrm{~s}$ taken as the minimum and maximum time step, respectively, was adopted during the calculation.

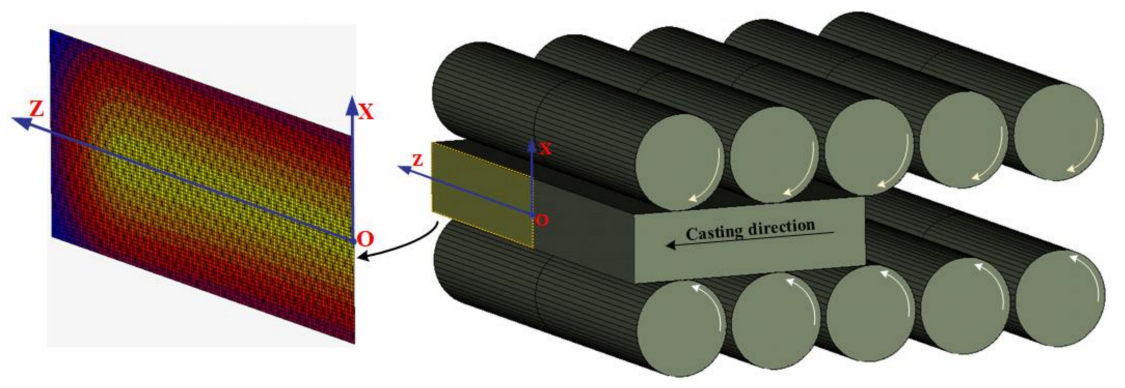

Figure 1. Schematic of the two-dimensional (2D) heat transfer model.

Table 1. The practical production conditions for the wide-thick slab continuous casting.

\begin{tabular}{cc}
\hline Item & Content \\
\hline Type of the continuous casting machine & Straight-bow wide-thick slab continuous casting machine \\
Main chemical composition of the studied steel grade $(\mathrm{wt} \%)$ & C: 0.17, Si: $0.15, \mathrm{Mn:} 0.60, \mathrm{P}: 0.015, \mathrm{~S}: 0.01$ \\
Slab transverse section size $(\mathrm{mm} \times \mathrm{mm})$ & $280 \times 2000$ \\
Casting speed $(\mathrm{m} / \mathrm{min})$ & 0.80 \\
Casting temperature $\left({ }^{\circ} \mathrm{C}\right)$ & $1520-1550$ \\
Length of each cooling zone $(\mathrm{m})$ & Effective mold height: 0.8, Secondary cooling zone: 19.7, Air \\
cooling zone: 9.8 \\
Specific water flow in the secondary cooling zone $(\mathrm{L} / \mathrm{kg})$
\end{tabular}

Thermal material properties and the cooling boundary conditions are two critical factors that influence the calculation accuracy of the 2D heat transfer model. In order to improve the calculation accuracy, thermal material properties of the studied steel grade, such as the conductivity, density, and enthalpy, were calculated with weighted averaging of phase fraction method [32-34], and the final thermal material properties of the studied steel grade can be found in our previous work. [34] In addition to thermal material properties, cooling boundary conditions is another critical factor that directly determines the calculation accuracy of the 2D heat transfer model. When compared with the conventional continuous casting slab with a relatively small section size, solidification of the wide-thick slab is obviously non-uniform along its width direction due to the large section size and the non-uniform water flux distribution in the secondary cooling zone of the continuous casting machine, and the final solidification region of the wide-thick slab was located around $1 / 8$ width of its transverse 
section $[33,34]$. In order to accurately determine the complicated cooling boundary conditions in the secondary cooling zone, the non-uniform cooling water flux distribution in this cooling zone was measured and applied during the calculation of cooling boundary conditions in the secondary cooling zone. More detailed information about the measured water flux distribution and the calculation method of the cooling boundary conditions in mold, secondary cooling zone, and air cooling zone for the studied wide-thick slab continuous casting machine could be found in our previous work [34].

\subsection{D Thermal-Mechanical Coupled Model}

In order to simulate the evolution of internal porosities in the wide-thick slab during HR, a 3D thermal-mechanical coupled model, as shown in Figure 2, was developed with MSC.Marc. Due to the symmetry of the strand deformation behavior during HR, a section of half the wide-thick slab along its width direction was taken as the calculation domain. The deformation of the wide-thick slab that is caused by HR is obviously much larger than the thermal deformation. Therefore, the much smaller thermal deformation of the wide-thick slab during HR was neglected in the 3D thermal-mechanical coupled model.
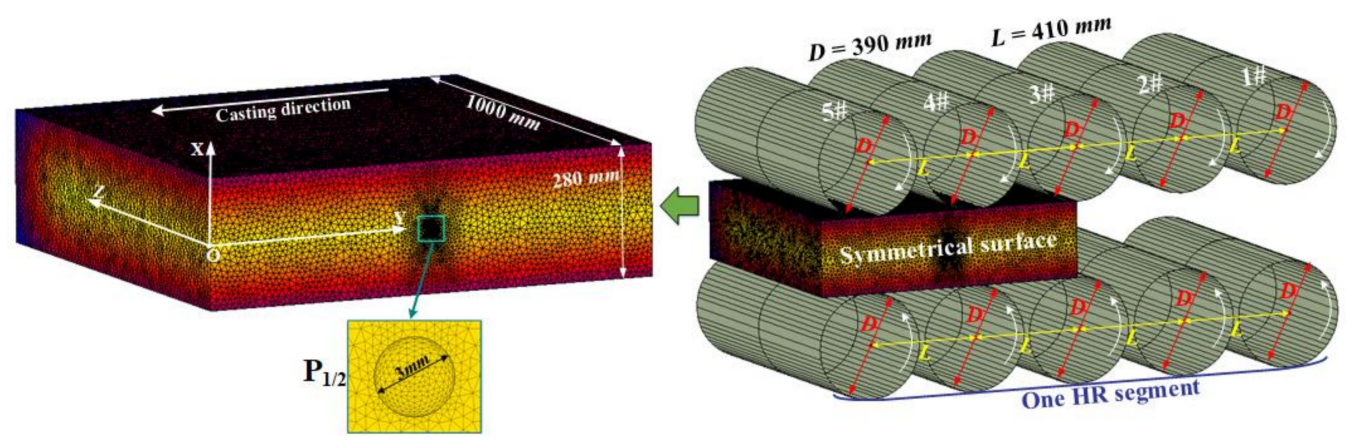

Figure 2. Schematic of the three-dimensional (3D) thermal-mechanical coupled model.

For the studied wide-thick slab continuous casting machine, HR can be implemented by one or several HR segments. Each HR segment, as shown in Figure 2, contains five pairs of rollers, and the roller diameter and roller pitch are $390 \mathrm{~mm}$ and $410 \mathrm{~mm}$, respectively. During HR, roller gap linearly decreases from entrance (Roller 1\#) to exit (Roller 5\#) of the segment, and rollers of the HR segment are regarded as rigid bodies without considering their small deformation during HR. The friction factor between rollers and the wide-thick slab was set as 0.3 [13] and the adopted contact detection method between rollers and the casting strand was node to segment contact algorithm [28].

During the calculation of the 3D thermal-mechanical coupled model, the slab temperature field at each increment was firstly solved by the solver based on the corresponding cooling boundary conditions and the thermal material properties. Secondly, the mechanical properties in the 3D thermal-mechanical coupled model were then updated mainly based on the temperature field at the present increment and the derived constitutive equations (Equations (1) and (2)), and the deformation behaviour of the wide-thick slab was then solved based on the mechanical boundary conditions during HR.

The practical production results, as shown in Figure 3, indicate that serious porosities are centrally distributed around the slab centerline, and the porosity size is usually less than $5 \mathrm{~mm}$. During the development of the 3D thermal-mechanical coupled model, porosity was simplified to be a spheroidal void with a diameter of $3 \mathrm{~mm}$ and located at the slab centerline. 


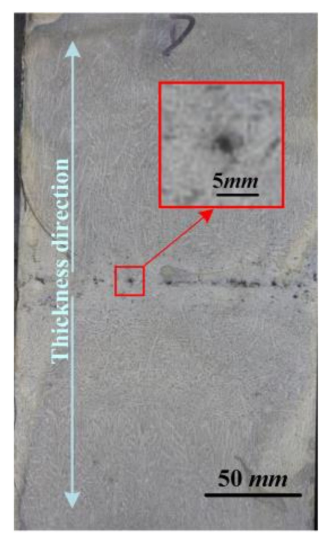

Figure 3. Macrographs of the wide-thick slab longitudinal section.

Due to the non-uniform solidification of the wide-thick slab, there still remains a small mushy region, as shown in Figure 4, around 1/8 width at the strand solidification end when the solid phase fraction $\left(f_{\mathrm{s}}\right)$ at the slab center of $1 / 2$ width reaches 1.0. This means that the temperature distribution and variation around the region of $1 / 8$ width differs from those at the other regions during HR at the strand solidification end, which will impact the porosity deformation behavior. Therefore, a total of two artificial spheroidal porosities (each with a diameter of $3 \mathrm{~mm}$ ) were created at the slab centerline of $1 / 8$ width $\left(\mathrm{P}_{1 / 8}\right)$ and $1 / 2$ width $\left(\mathrm{P}_{1 / 2}\right)$ in the $3 \mathrm{D}$ thermal-mechanical coupled model for investigating the porosity deformation behavior in these two typical regions during HR. Figure 4 schematically shows the distribution of these two artificial porosities on the slab transverse section in the 3D thermal-mechanical coupled model, and the artificial porosity located at $1 / 2$ width $\left(\mathrm{P}_{1 / 2}\right)$ in Figure 4 can be also seen in Figure 2 and it is located on the symmetrical surface of the 3D thermal-mechanical coupled model.

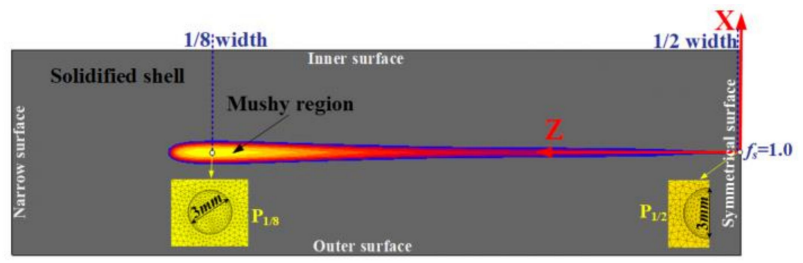

Figure 4. Solidification morphology of the wide-thick slab transverse section when solid phase fraction $\left(f_{\mathrm{s}}\right)$ at the slab center reaches 1.0, and the distribution of the two artificial porosities on slab the transverse section in the 3D thermal mechanical model.

In order to improve the calculation accuracy and efficiency, the calculation domain of the 3D thermal-mechanical coupled model was nonuniformly meshed with four-nodes tetrahedral elements. Fine elements with a side length of $\sim 0.3 \mathrm{~mm}$ are distributed around the two artificial porosities, while coarser elements with a side length of $\sim 10 \mathrm{~mm}$ are distributed around the slab surface. The final 3D thermal-mechanical coupled model contains 540,836 elements and 99,592 nodes. Automatic time step was adopted during the simulation, and the maximum and the minimum time step were $0.01 \mathrm{~s}$ and $1 \mathrm{~s}$, respectively.

In order to accurately describe the metal flow behavior of the wide-thick slab during HR, the true stress-strain of the studied steel grade was measured at different temperatures and strain rates, and the measured results are presented in Figure 5. 


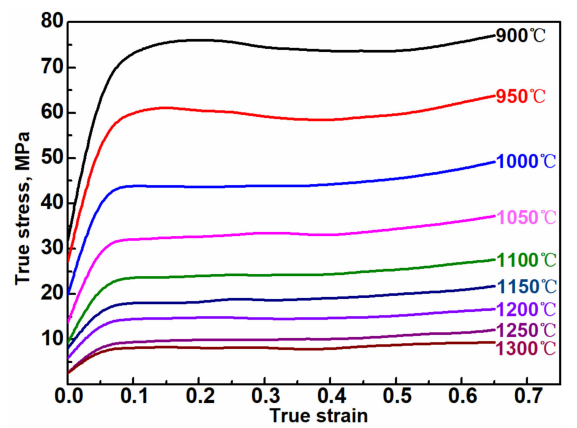

(a)

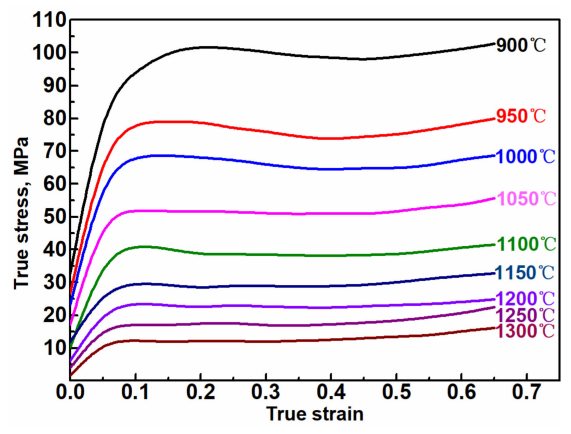

(b)

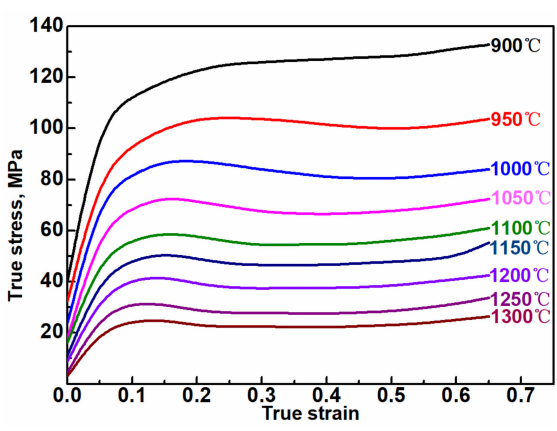

(c)

Figure 5. The measured true stress-strain at different temperature and strain rate of (a) $0.001 \mathrm{~s}^{-1}$, (b) $0.01 \mathrm{~s}^{-1}$, and (c) $0.1 \mathrm{~s}^{-1}$.

Based on the measured results in Figure 5, an Arrhenius-type constitutive model was derived with the similar method adopted in our previous work for establishing an Arrhenius-type constitutive model of GCr15 steel [35]. The derived constitutive model of the studied steel was then applied to the 3D thermal-mechanical coupled model, and the strain and stress in the constitutive model were adopted as equivalent strain and equivalent stress in the $3 \mathrm{D}$ thermal-mechanical coupled model. The derived constitutive model can be expressed, as follows:

$$
\left\{\begin{array}{l}
\sigma=\frac{1}{\alpha}\left\{\left(\frac{Z}{A}\right)^{1 / n}+\left[\left(\frac{Z}{A}\right)^{2 / n}+1\right]^{1 / 2}\right\}, \\
Z=\dot{\varepsilon} \cdot \exp \left(\frac{Q}{R(T+273)}\right)
\end{array}\right.
$$

where $\sigma$ is the stress, $\mathrm{MPa} ; A$ and $\alpha$ are material constants; $n$ is the material's stress index; $Z$ is the Zenner-Hollomon parameter; $\dot{\varepsilon}$ is the strain rate, $\mathrm{s}^{-1} ; Q$ is the activation energy of hot deformation, $\mathrm{J} \mathrm{mol}^{-1}$; $R$ is the ideal gas constant, $\left(8.314 \mathrm{~J} \mathrm{~mol}^{-1} \mathrm{~K}^{-1}\right)$; and, $T$ is the temperature, ${ }^{\circ} \mathrm{C}$. The strain-dependent parameters of $\alpha, A, n$, and $Q$ were derived based on the measured true stress-strain curves and could be calculated with Equation (2) and the corresponding parameters that are listed in Table 2.

$$
\left\{\begin{array}{l}
Q=B_{0}+B_{1} \varepsilon^{1}+B_{2} \varepsilon^{2}+B_{3} \varepsilon^{3}+B_{4} \varepsilon^{4}+B_{5} \varepsilon^{5}+B_{6} \varepsilon^{6} \\
\ln A=C_{0}+C_{1} \varepsilon^{1}+C_{2} \varepsilon^{2}+C_{3} \varepsilon^{3}+C_{4} \varepsilon^{4}+C_{5} \varepsilon^{5}+C_{6} \varepsilon^{6} \\
n=D_{0}+D_{1} \varepsilon^{1}+D_{2} \varepsilon^{2}+D_{3} \varepsilon^{3}+D_{4} \varepsilon^{4}+D_{5} \varepsilon^{5}+D_{6} \varepsilon^{6} \\
\alpha=E_{0}+E_{1} \varepsilon^{1}+E_{2} \varepsilon^{2}+E_{3} \varepsilon^{3}+E_{4} \varepsilon^{4}+E_{5} \varepsilon^{5}+E_{6} \varepsilon^{6}
\end{array},\right.
$$


Table 2. Polynomial fitting coefficients of the material parameters ( $X$ represents $B, C, D$, and $E$ in Equation (2)).

\begin{tabular}{ccccc}
\hline Items & $\boldsymbol{Q} \mathbf{( \mathbf { J ~ m o l } ^ { - \mathbf { 1 } } \mathbf { ) }}$ & $\ln \boldsymbol{A}$ & $\boldsymbol{n}$ & $\boldsymbol{\alpha}$ \\
\hline $900{ }^{\circ} \mathrm{C}$ to $1300{ }^{\circ} \mathrm{C}$ & & & & \\
$X_{0}$ & 730674.0 & 57.78 & 6.25 & 0.03965 \\
$X_{1}$ & -7080560.0 & -607.39 & -42.11 & -0.35051 \\
$X_{2}$ & 59878600.0 & 5157.77 & 295.89 & 3.09951 \\
$X_{3}$ & -237768000.0 & -20523.01 & -1053.31 & -12.63650 \\
$X_{4}$ & 488739000.0 & 42240.95 & 2024.39 & 26.65368 \\
$X_{5}$ & -502960000.0 & -43514.69 & -1978.96 & -28.32745 \\
$X_{6}$ & 204463000.0 & 17705.26 & 767.78 & 11.95993 \\
\hline
\end{tabular}

For temperature of $>1300{ }^{\circ} \mathrm{C}$,

$$
\sigma=\eta \sigma_{1300}
$$

where $\sigma_{1300}$ is the flow stress at $1300{ }^{\circ} \mathrm{C}$ and a certain specified strain rate and strain and can be determined by Equation (1); $\eta$ is the temperature-dependent attenuation coefficient and it can be expressed as:

$$
\eta=\frac{1}{\sigma_{\mathrm{p} 1300}} c(T+273)^{d}
$$

where $\sigma_{\mathrm{p} 1300}$ is the peak stress of the measured true stress-strain curve at $1300{ }^{\circ} \mathrm{C}$ and $0.001 \mathrm{~s}^{-1}$ and equal to 8.431; and, $T$ is the temperature of $>1300{ }^{\circ} \mathrm{C} ; c$ and $d$ are equal to $5.898 \times 1018$ and -5.712 , respectively, based on the variation trend of peak stress with temperature at the strain rate of $0.001 \mathrm{~s}^{-1}$.

\subsection{Model Validation}

In order to show the accuracy of the derived Arrhenius-type constitutive model, flow stress under different temperature and strain rates was calculated with this constitutive model, and the calculated results are compared with the measured ones in Figure 6. Based on the measured and the calculated results in Figure 6, the standard statistical parameters of average absolute relative error (AARE) for the measured and the calculated values, which has been adopted in our previous work [35], was calculated with Equation (5). It is found that the value of $A A R E$ is about $4.7 \%$, which proves the accuracy of the derived constitutive model.

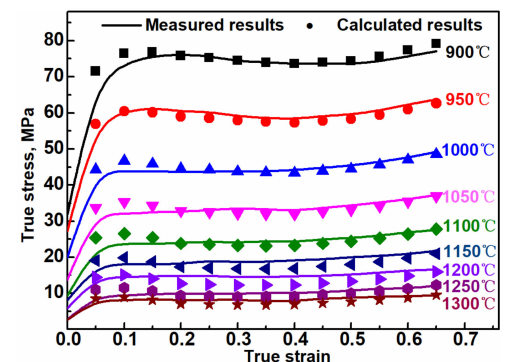

(a)

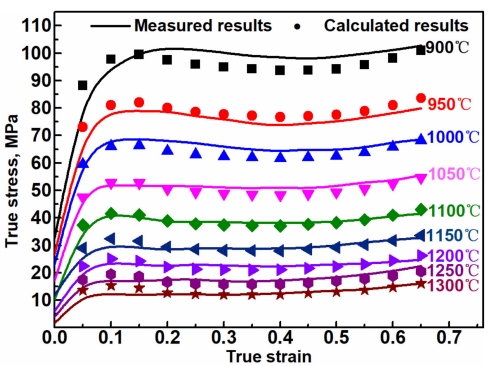

(b)

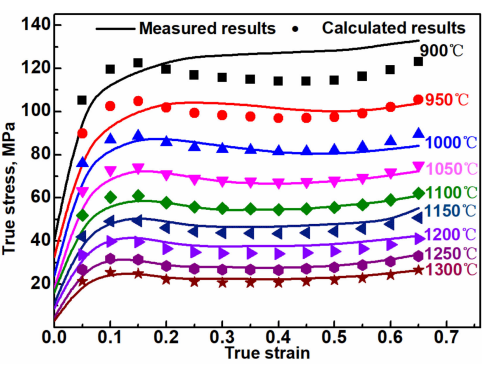

(c)

Figure 6. Comparison between the measured and the calculated results at different temperature and strain rate of (a) $0.001 \mathrm{~s}^{-1}$, (b) $0.01 \mathrm{~s}^{-1}$, and (c) $0.1 \mathrm{~s}^{-1}$. 


$$
\operatorname{AARE}(\%)=\frac{1}{N} \sum_{i=1}^{N}\left|\frac{E_{i}-P_{i}}{E_{i}}\right| \times 100 \%,
$$

where $E_{i}$ is the measured value and $P_{i}$ is the calculated value by the derived constitutive model; and, $N$ is the total number of data sets in Figure 6.

In order to verify the accuracy of the 2D heat transfer model, the temperature of the slab inner surface at different strand positions were measured with a thermal infrared camera (A40, FLIR, FLIR Systems Inc., Goleta, CA, USA) when the wide-thick slab with a transverse section size of $2000 \mathrm{~mm} \times 280 \mathrm{~mm}$ was cast at $0.8 \mathrm{~m} / \mathrm{min}$. The measured results are compared with the calculated ones in Figure 7, which indicates that the calculated temperature by the 2D heat transfer model agree well with the corresponding measured results and that the relative error between the calculated and the measured results is less than $2.2 \%$.

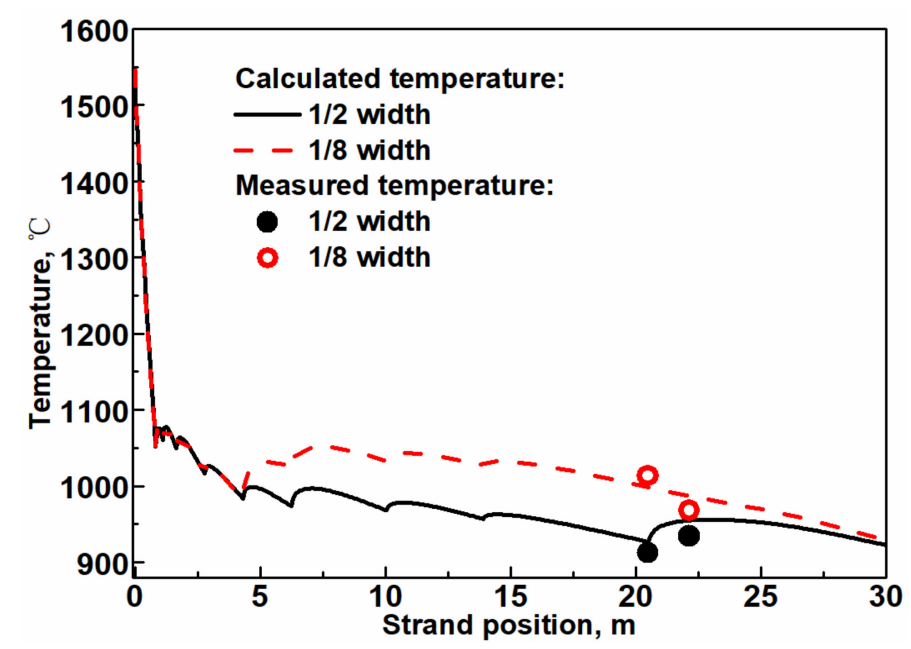

Figure 7. Comparison between the calculated and the measured temperature.

It should be noted that, due to the non-uniform cooling water flux distribution in the secondary cooling zone, the slab surface temperature at $1 / 8$ width, as shown in Figure 7 , is higher than that at $1 / 2$ width. For this reason, the obvious mushy region, as has been presented in Figure 4 , still could be observed around $1 / 8$ width when $f_{\mathrm{s}}$ reaches 1.0 at the strand solidification end.

In order to verify the 3D thermal-mechanical coupled model, plant trial of HR was carried out. During the plant trial, the casting strand of the wide-thick slab moved through the HR segment from entrance (Roller 1\#) to exit (Roller 5\#) and $f_{s}$ (solid phase fraction at the slab center) at the entrance of the HR segment is 1.0. The reduction force of the HR segment was measured in real time by the pressure sensors that were installed in the hydraulic cylinders of the HR segment. The calculated reduction force of the HR segment in the 3D thermal-mechanical coupled model can be determined by adding up the calculated reduction force of Roller $1 \#-5 \#$. Figure 8 compares the actual measured reduction force of the HR segment during plant trial with the corresponding calculated results by the $3 \mathrm{D}$ thermal-mechanical coupled model. It can be seen that the calculated reduction force shows good agreement with the actual measured results. The relative error between the calculated and the actual measured results is less than $3.2 \%$. 


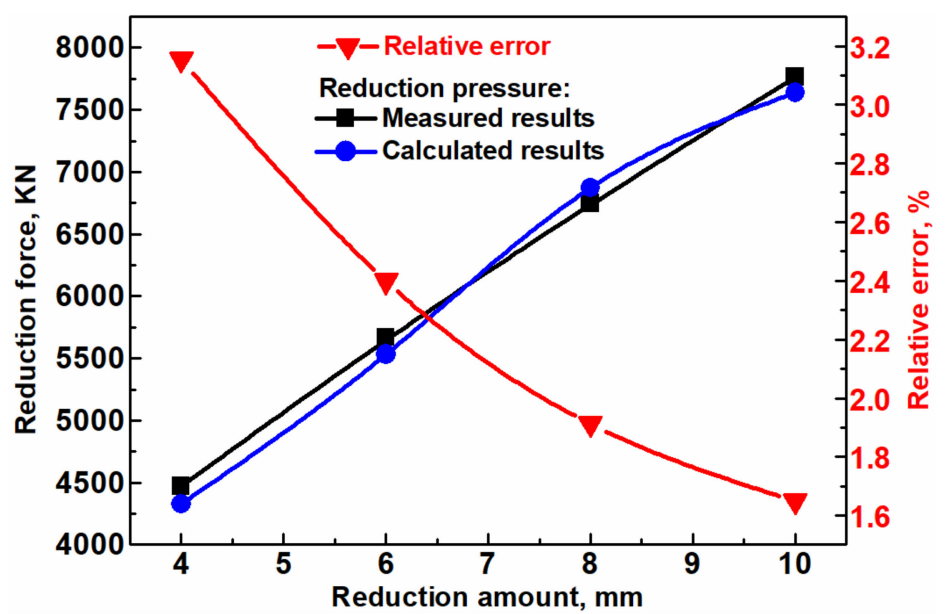

Figure 8. Comparison between the measured and the calculated reduction force.

\section{Results and Discussion}

Figure 9 schematically shows the porosity dimension along the slab thickness direction (corresponding to $X$ axis), casting direction (corresponding to $Y$ axis), and the slab width direction (corresponding to $Z$ axis) for the two created artificial porosities in the 3D thermal-mechanical coupled. In order to quantitatively describe the porosity deformation behavior along three axis directions, the porosity deformation degree was defined:

$$
\left\{\begin{array}{l}
\Delta l_{x}=\ln \left(\frac{L_{x}^{\prime}}{L_{x}}\right) \\
\Delta l_{y}=\ln \left(\frac{L_{y}^{\prime}}{L_{y}}\right), \\
\Delta l_{z}=\ln \left(\frac{L_{z}^{\prime}}{L_{z}}\right)
\end{array}\right.
$$

where $\Delta l_{x}, \Delta l_{y}$, and $\Delta l_{z}$ are the porosity deformation degree along the slab thickness direction, casting direction, and the slab width direction; $L_{x}, L_{y}$, and $L_{z}$ are the porosity axis length along three axis directions before HR; $L^{\prime}{ }_{x}, L^{\prime} y$, and $L_{z}^{\prime}$ are porosity axis length along three axis directions after HR.
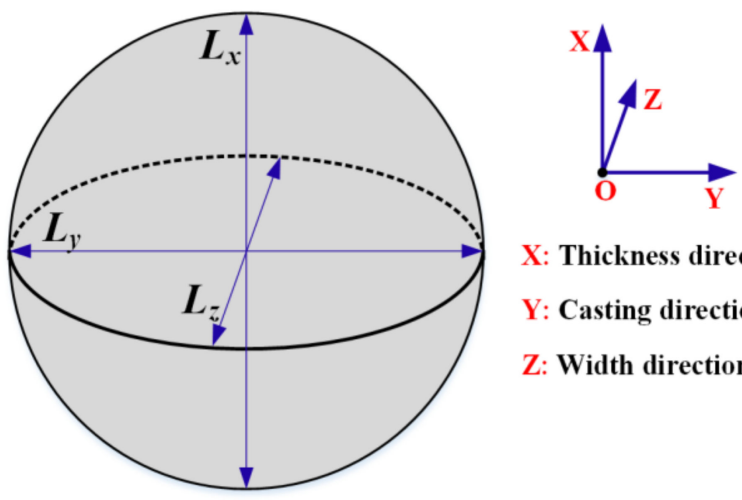

$\mathrm{X}$ : Thickness direction

Y: Casting direction

$\mathrm{Z}$ : Width direction

Figure 9. Schematic of the porosity dimension along three axis directions.

In order to quantitatively describe the overall deformation behavior of each artificial porosity in the 3D thermal-mechanical coupled model and evaluate the process effect of HR on improving the internal porosity, the porosity closure degree was defined based on the porosity axis length before and after HR:

$$
\eta_{\mathrm{s}}=\frac{2 L_{x}}{\left(L_{\mathrm{y}}+L_{z}\right)}-\frac{2 L_{x}^{\prime}}{\left(L_{\mathrm{y}}^{\prime}+L_{z}^{\prime}\right)},
$$


where $\eta_{s}$ is the porosity closure degree after $H R$ and it ranges from 0 to 1 . A larger value of $\eta_{s}$ indicates a better process effect of HR on improving the internal porosity.

\subsection{Porosity Deformation Behavior after Different HR Deformation}

The porosity deformation behavior was firstly investigated under the condition that different HR deformation was uniformly implemented by the HR segment at the strand solidification end $\left(f_{\mathrm{s}}\right.$ at the entrance of the HR segment is 1.0). The porosity deformation degree and the closure degree of $\mathrm{P}_{1 / 2}$ and $\mathrm{P}_{1 / 8}$ after different HR deformation are presented in Figure 10. The thickness reduction in each figure represents the magnitude of HR deformation implemented by the HR segment.

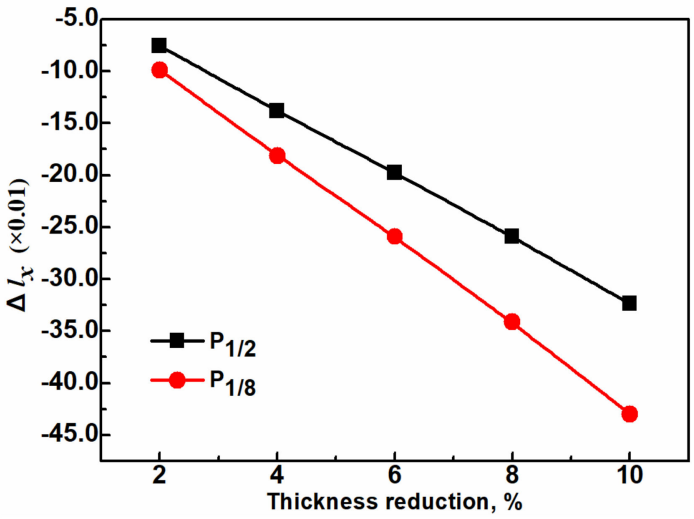

(a)

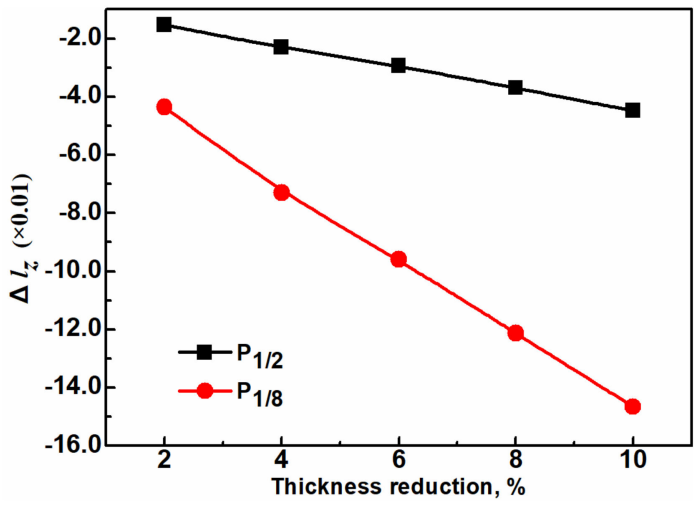

(c)

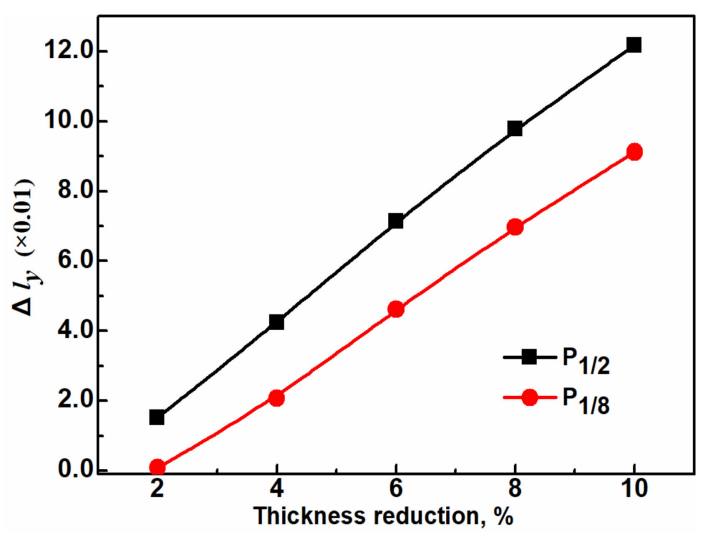

(b)

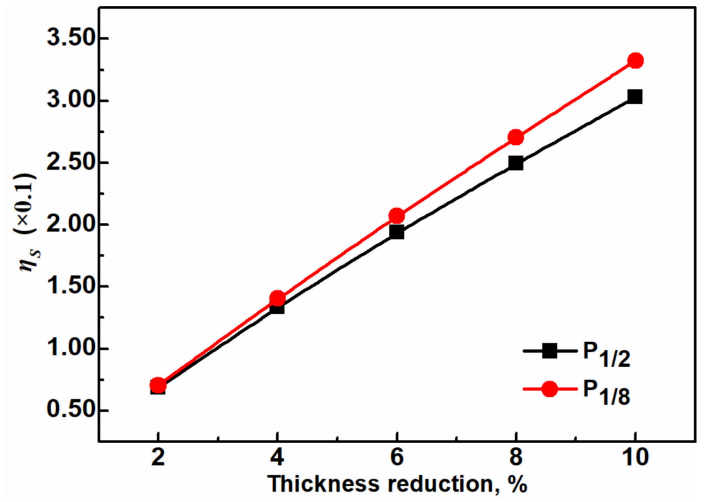

(d)

Figure 10. Porosity deformation degree along the (a) slab thickness direction, (b) casting direction, (c) width direction, and (d) the porosity closure degree after different heavy reduction (HR) deformation.

It can be seen from Figure 10a to $\mathrm{c}$ that the porosity deformation degree along the slab thickness direction $\left(\Delta l_{x}\right)$, the casting direction $\left(\Delta l_{y}\right)$, and the slab width direction $\left(\Delta l_{z}\right)$ continuously increase with thickness reduction (represents the HR deformation implemented by the HR segment) increased. The values of $\Delta l_{x}$ in Figure 10a and $\Delta l_{z}$ in Figure 10c are negative, which is opposite to that of $\Delta l_{y}$ in Figure 10b. This means that the porosity size decreases along the slab thickness direction and the slab width direction, and it meanwhile increases along the casting direction during HR. When compared with the porosity deformation degree along the casting direction $\left(\Delta l_{y}\right)$ and the slab width direction $\left(\Delta l_{z}\right)$, the magnitude of $\Delta l_{x}$ is much larger, which indicates that the major deformation of the porosity is along the slab thickness direction. During HR, the internal porosity is continuously improved with the implemented HR deformation increase. As a result, an increasing trend for the porosity closure degree $\left(\eta_{\mathrm{s}}\right)$ can be observed in Figure 10d. 
Figure 10 also indicates that there exists difference between the deformation behavior of $\mathrm{P}_{1 / 2}$ and that of $\mathrm{P}_{1 / 8}$, and the closure degree of $\mathrm{P}_{1 / 8}$ is $9.7 \%$ larger than that of $\mathrm{P}_{1 / 2}$ after $10 \% \mathrm{HR}$ deformation. This indicates that the porosity at the slab center around $1 / 8$ width can be improved more effectively during $\mathrm{HR}$ at the strand solidification end. Two possible factors may contribute to the difference of porosity deformation behavior at $1 / 8$ width and $1 / 2$ width: the different location of $\mathrm{P}_{1 / 8}$ and $\mathrm{P}_{1 / 2}$ and the different temperature distribution around $1 / 8$ width and $1 / 2$ width.

In order to investigate the influence of porosity location, the deformation behavior of $\mathrm{P}_{1 / 8}$ and $\mathrm{P}_{1 / 2}$ was calculated under the condition that the cooling water flux distribution in the secondary cooling zone of the wide-thick slab continuous casting machine and the corresponding solidification process of the wide-thick slab were assumed to be uniform along the slab width direction. As the porosity mainly deforms along the slab thickness direction, only the porosity deformation degree along the slab thickness direction $\left(\Delta l_{x}\right)$ and the porosity closure degree at $1 / 8$ width and $1 / 2$ width are compared in Figure 11a and b, respectively. The comparison results in Figure 11 show that the difference between the porosity deformation behaviour at $1 / 8$ width and $1 / 2$ width during HR is very small. This indicates that the influence of porosity location on the porosity deformation behavior during HR is not obvious under uniform cooling condition and also simultaneously proves that the difference of porosity deformation behavior at $1 / 8$ width and $1 / 2$ width is mainly caused by the different temperature distribution around these two regions.

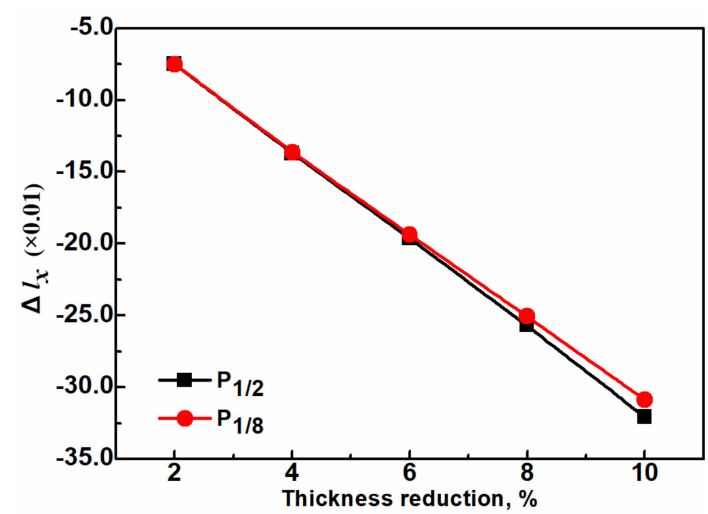

(a)

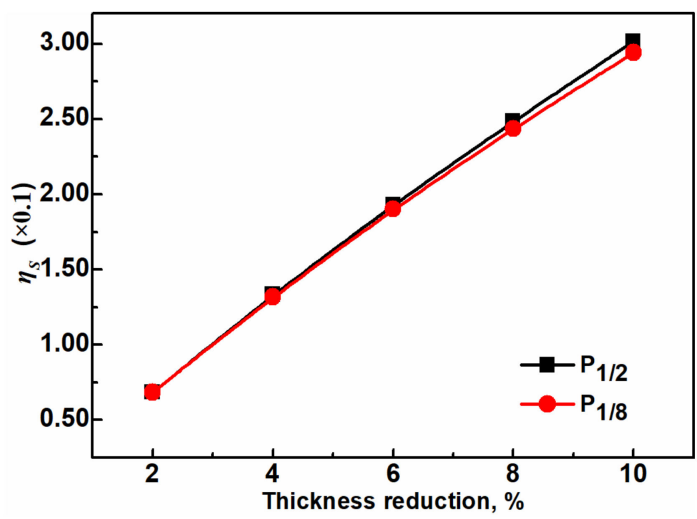

(b)

Figure 11. (a) Porosity deformation degree along the thickness direction and (b) porosity closure degree after different HR deformation implemented at the strand solidification end under condition of uniform solidification.

In order to further clarify the influence of temperature distribution on the porosity deformation behavior at $1 / 8$ width and $1 / 2$ width during $H R$, the variation of temperature, and the corresponding temperature difference at different typical locations $\left(L_{\mathrm{S}}{ }^{1 / 8}, L_{\mathrm{C}}{ }^{1 / 8}, L_{\mathrm{S}}{ }^{1 / 2}, L_{\mathrm{C}}{ }^{1 / 2}\right)$ shown in Figure $12 \mathrm{a}$ during HR at the strand solidification end are compared in Figure $12 \mathrm{~b}, \mathrm{c}$, respectively. $T_{\mathrm{s}}{ }^{1 / 8}, T_{\mathrm{C}}{ }^{1 / 8}, T_{\mathrm{s}}{ }^{1 / 2}$, $T_{\mathrm{c}}{ }^{1 / 2}$ in Figure $12 \mathrm{~b}$ are the calculated temperature at $L_{\mathrm{S}}{ }^{1 / 8}, L_{\mathrm{C}}{ }^{1 / 8}, L_{\mathrm{S}}{ }^{1 / 2}, L_{\mathrm{C}}{ }^{1 / 2}$ respectively, and $\Delta T^{1 / 8}$ $\left(\Delta T^{1 / 8}=T_{\mathrm{c}}{ }^{1 / 8}-T_{\mathrm{s}}{ }^{1 / 8}\right)$ and $\Delta T^{1 / 2}\left(\Delta T^{1 / 2}=T_{\mathrm{c}}{ }^{1 / 2}-T_{\mathrm{s}}{ }^{1 / 2}\right)$ in Figure $12 \mathrm{c}$ represent the temperature difference between the slab surface and center at $1 / 8$ width and $1 / 2$ width, respectively.

It can be seen from Figure $12 \mathrm{~b}$ that temperature at different typical locations overall present a decreasing trend from entrance (Roller 1\#) to exit (Roller 5\#) of the HR segment during HR at the strand solidification end. However, when compared with the gradual temperature variation at the slab surface $\left(T_{\mathrm{s}}{ }^{1 / 8}\right.$ and $\left.T_{\mathrm{s}}{ }^{1 / 8}\right)$, temperature variation at the slab center $\left(T_{\mathrm{c}}{ }^{1 / 8}\right.$ and $\left.T_{\mathrm{c}}{ }^{1 / 2}\right)$ are much more remarkable. As a result, the variation trend of $\Delta T^{1 / 8}$ and $\Delta T^{1 / 2}$ in Figure $12 \mathrm{c}$ are similar with that of $T_{\mathrm{c}}{ }^{1 / 8}$ and $T_{\mathrm{c}}{ }^{1 / 2}$ in Figure $12 \mathrm{~b}$. As mentioned above, a small mushy region still remains around $1 / 8$ width at the strand solidification end when $f_{\mathrm{s}}$ reaches 1.0 . This means that the decrease of $T_{\mathrm{C}}{ }^{1 / 8}$ and $\Delta T^{1 / 8}$ during HR at the strand solidification end can be slowed down to some extent by the released 
latent heat from the remained small mushy region around $1 / 8$ width. For this reason, the temperature difference at $1 / 8$ width $\left(\Delta T^{1 / 8}\right)$, as shown in Figure $12 \mathrm{c}$, is larger than that at $1 / 2$ width $\left(\Delta T^{1 / 2}\right)$ during $\mathrm{HR}$, except at the entrance (Roller 1\#) of the HR segment. Combined with the larger closure degree of $\mathrm{P}_{1 / 8}$ than that of $\mathrm{P}_{1 / 2}$ in Figure $10 \mathrm{~d}$, it can be concluded that, due to the larger temperature difference at $1 / 8$ width, porosity around this region can be improved more effectively by HR at the strand solidification end.

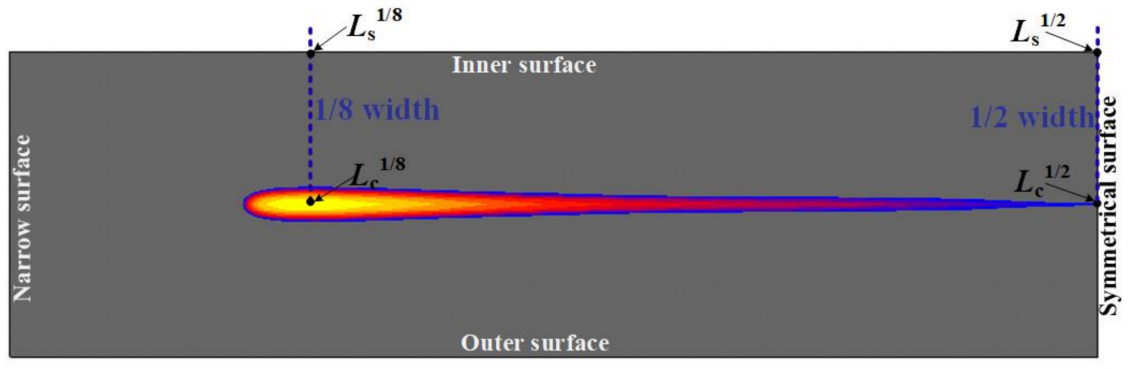

(a)

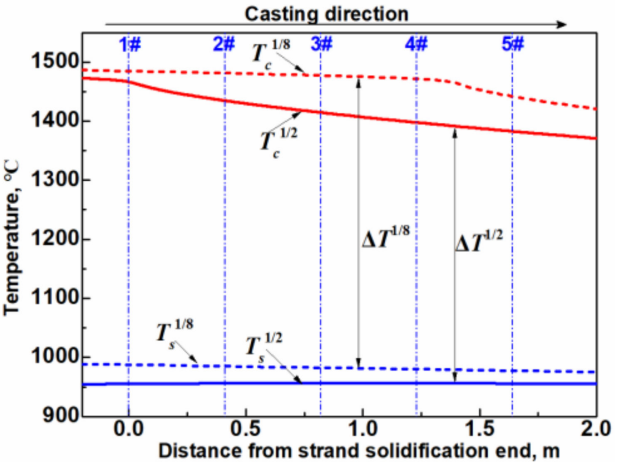

(b)

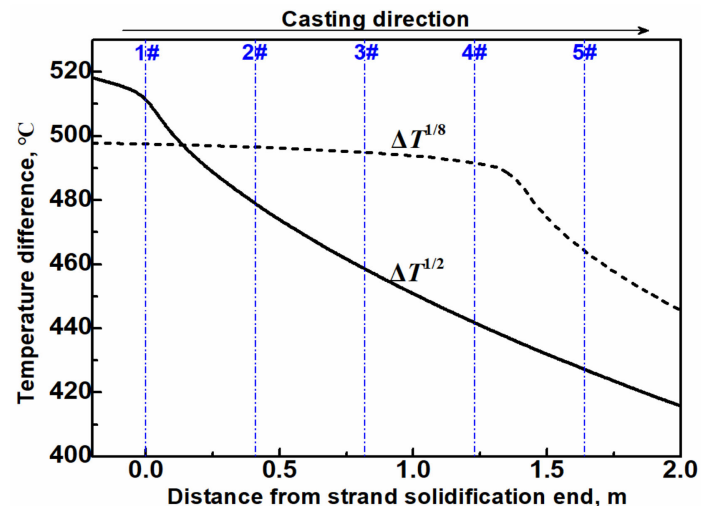

(c)

Figure 12. (a) Distribution of the typical locations on the slab transverse section and variation of the (b) temperature and (c) temperature difference at the typical locations during HR.

During the hot working process, the deformation degree at one position of the workpiece can be quantitatively evaluated by the corresponding equivalent strain, and for this reason, many previous researchers [6-9] adopted equivalent strain as an indicator of closure degree of internal porosity in workpiece.

Figure 13 compares the equivalent strain at $L_{\mathrm{C}}{ }^{1 / 8}$ (corresponding to the location of $\mathrm{P}_{1 / 8}$ ) and $L_{\mathrm{C}}{ }^{1 / 2}$ (corresponding to the location of $\mathrm{P}_{1 / 2}$ ) after different $\mathrm{HR}$ deformation implemented by the $\mathrm{HR}$ segment at the strand solidification end. It can be seen that, when the HR deformation increased, equivalent strain at $L_{\mathrm{C}}{ }^{1 / 8}$ and $L_{\mathrm{c}}{ }^{1 / 2}$ after $\mathrm{HR}$ continuously increase. As a result, the porosity at $1 / 8$ width and $1 / 2$ width can be continuously improved, and the corresponding porosity closure degree in Figure 10d shows a rising trend with HR deformation increased. However, it should be noted that the equivalent strain at $L_{c}{ }^{1 / 8}$ is overall larger than that at $L_{c}{ }^{1 / 2}$. This proves that, due to the larger temperature difference at $1 / 8$ width, as mentioned above, HR deformation can transfer from the slab surface into its center more effectively for better improving the internal porosities around this region. 


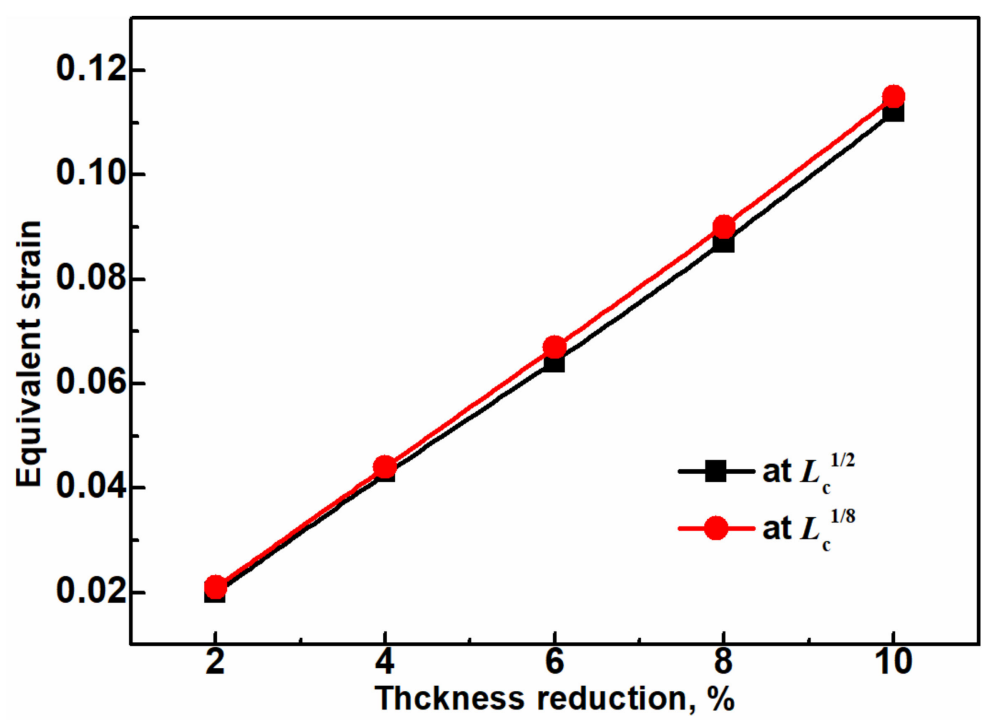

Figure 13. Equivalent strain at the slab center of $1 / 8$ width $\left(L_{\mathrm{c}}{ }^{1 / 8}\right)$ and $1 / 2$ width $\left(L_{\mathrm{c}}{ }^{1 / 2}\right)$ after different HR deformation implemented at the strand solidification end.

\subsection{Influence of HR Position on the Porosity Deformation Behavior}

For the studied wide-thick slab continuous casting machine, HR can be implemented by one or more HR segments, and the reduction position can be flexibly changed by adjusting the roller gap of the corresponding HR segment. In order to study the influence of HR position on the porosity deformation behavior, the porosity deformation behavior was calculated with $6 \% \mathrm{HR}$ deformation implemented by one HR segment at different strand position.

Figure $14 \mathrm{a}-\mathrm{d}$ show the calculated porosity deformation behavior, and the abscissa axis in each figure represents the HR start position (corresponding to Roll $1 \#$ of the HR segment) after the strand solidification end. With HR start position moving away after the strand solidification end, the porosity deformation degree along the slab thickness direction in Figure 14a and along the slab width direction in Figure 14c both decrease, while the porosity deformation degree along the casting direction in Figure 14b presents an increasing trend. This indicates that, with the HR starting position moving away after the strand solidification end, the porosity size after HR increases along three axis directions. Figure 14d shows the porosity closure degree after HR implemented at different strand positions. When compared with the porosity closure degree after HR implemented at the strand solidification end, the closure degree of $\mathrm{P}_{1 / 8}$ and $\mathrm{P}_{1 / 2}$ decrease by $9.3 \%$ and $6.3 \%$, respectively, with the HR starting position moving away by $3 \mathrm{~m}$ after the strand solidification end, which indicates that the process effect of HR on improving the internal porosity becomes worse with the HR starting position moving away after the strand solidification end.

Figure $15 \mathrm{a}, \mathrm{b}$, respectively, presents the average temperature difference between the slab surface and center within the HR segment and the equivalent strain after $6 \% \mathrm{HR}$ deformation implemented at different strand position. With the HR starting position moving away after the strand solidification end, the average temperature difference, which could promote the transfer of HR deformation from the slab surface into its center, significantly decreases. As a result, the equivalent strain, which represents the material deformation degree and is regarded as an indicator of porosity closure degree, after HR shown in Figure $15 \mathrm{~b}$ continuously decreases, which explains the continuously decreasing trend of $\eta_{\mathrm{s}}$ in Figure 15d. 


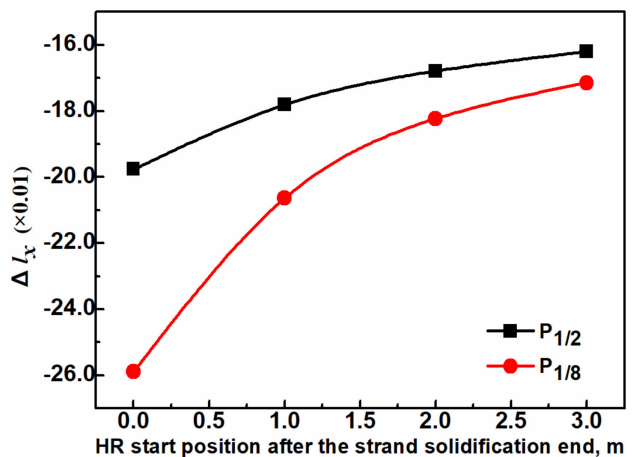

(a)

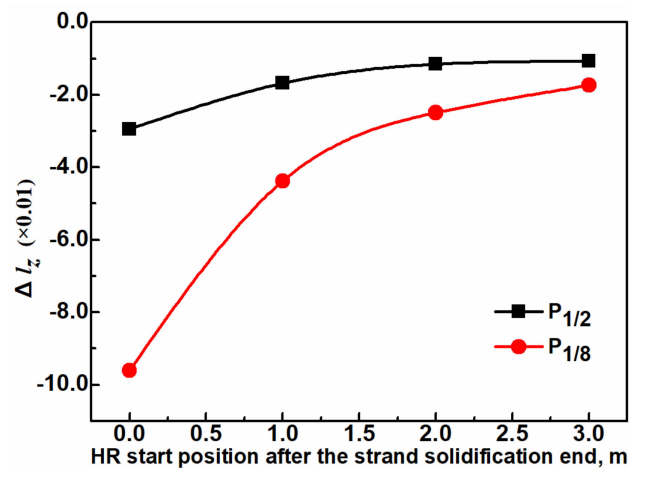

(c)

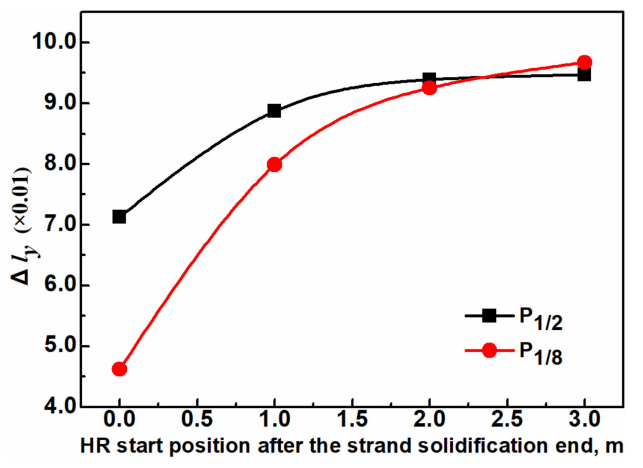

(b)

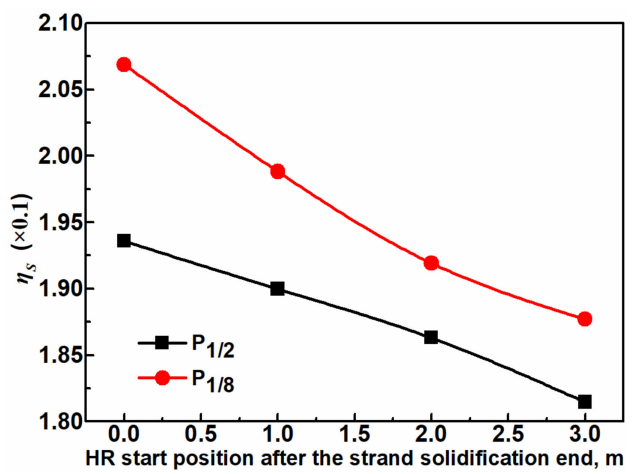

(d)

Figure 14. Porosity deformation degree along the (a) slab thickness direction, (b) casting direction, (c) slab width direction, and (d) the porosity closure degree after $6 \%$ HR deformation implemented at different strand position.

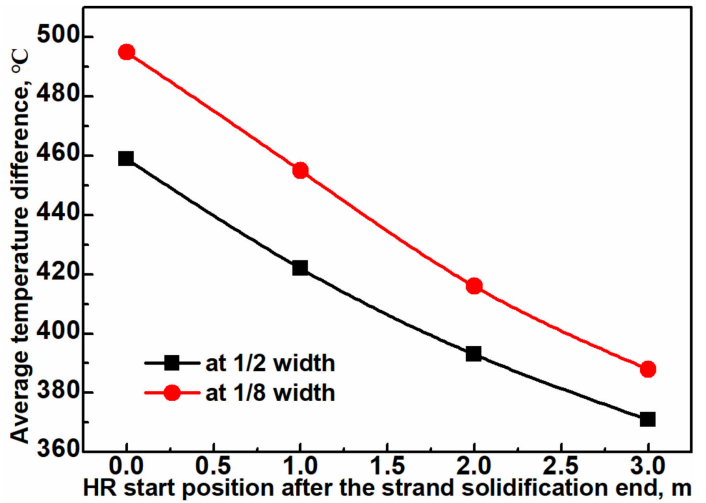

(a)

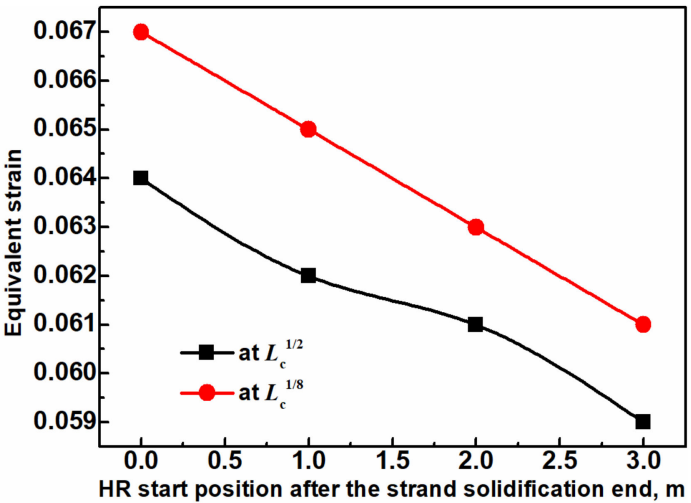

(b)

Figure 15. (a) The average temperature difference at $1 / 8$ width and $1 / 2$ width within the HR segment and (b) the equivalent strain at the slab center of $1 / 8$ width $\left(L_{\mathrm{c}}{ }^{1 / 8}\right)$ and $1 / 2$ width $\left(L_{\mathrm{c}}{ }^{1 / 2}\right)$ after $6 \% \mathrm{HR}$ deformation implemented at different strand position.

With the HR starting position moving away after the strand solidification end, the temperature of the casting strand decreases, and its deformation-resistant ability during HR correspondingly increases. As a result, the required reduction force for the HR segment to implement the same HR deformation, as shown in Figure 16, significantly increases with the HR start position moving away after the strand solidification end. When compared with the required reduction force for the HR segment to implement $6 \% \mathrm{HR}$ deformation at the strand solidification end, this value increases by $20 \%$ with the HR starting position moving away by $3 \mathrm{~m}$ after the strand solidification end. This indicates that the reduction 
capacity of the HR segment will significantly decrease with the HR starting position moving away after the strand solidification end.

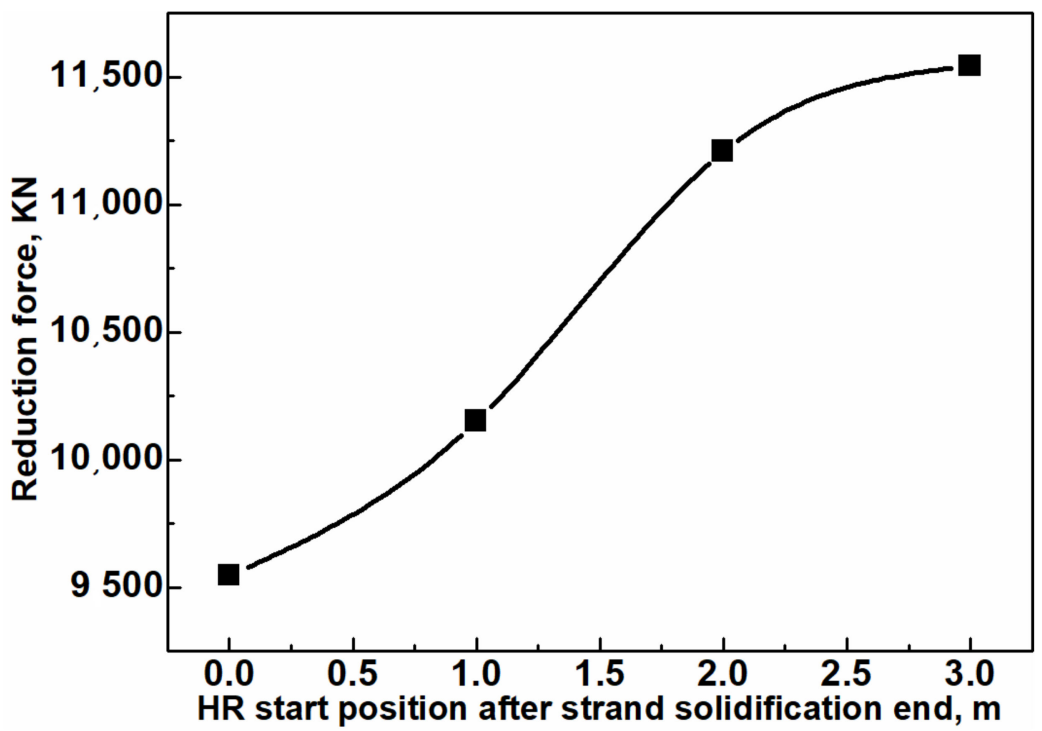

Figure 16. The required reduction force for the HR segment to implement $6 \%$ HR deformation at different strand position.

From the discussion above, it can be concluded that, due to the significant decrease of porosity closure degree and the reduction capacity of the HR segment, the HR efficiency on improving the internal porosities significantly decreases with the HR starting position moving away after the strand solidification end.

\subsection{Influence of Reduction Mode on the Porosity Deformation Behavior}

In order to implement HR more effectively and thus better improve the internal porosities, the influence of reduction mode on the porosity deformation behavior during HR was investigated. Table 3 compares the HR deformation distribution within the HR segment in five cases, and the variation of the corresponding slab thickness from entrance (Roller 1\#) to exit (Roller 5\#) of the HR segment are presented in Figure 17. The total HR deformation in each case is $6.0 \%$. In Case 1, HR deformation is uniformly implemented with $1.2 \%$ HR deformation at each roller of the HR segment, which represents the traditional reduction mode and it is called UHR (Uniform Heavy Reduction) in the present work. In addition to UHR, a new reduction mode, called SPUHR (Single Point and Uniform Heavy Reduction), was proposed based on the mechanical structure of the HR segment. For SPUHR (corresponding to Case 2 to 5), a relatively larger HR deformation was implemented at Roller 1\# by adjusting the hydraulic cylinders that were installed at the entrance of the HR segment. The residual HR deformation was then uniformly implemented from Roller 2\# to 5\# with a relatively smaller HR deformation at each roller than that at Roller 1\#, and the HR deformation at each roller of 2\# to $5 \#$ was equal due to the limitation of mechanical structure of the HR segment.

Table 3. HR deformation distribution within the HR segment in five cases.

\begin{tabular}{ccccccccc}
\hline \multirow{2}{*}{ Case } & \multirow{2}{*}{ Reduction mode } & \multicolumn{3}{c}{ Thickness reduction at each roller of the HR segment, \% } & \multicolumn{2}{c}{ Total thickness } \\
& & 1\# & 2\# & 3\# & 4\# & 5\# & reduction, \% \\
\hline 1 & UHR & 1.20 & 1.20 & 1.20 & 1.20 & 1.20 & 6.0 \\
2 & & 1.80 & 1.05 & 1.05 & 1.05 & 1.05 & 6.0 \\
3 & \multirow{2}{*}{ SPUHR } & 2.40 & 0.90 & 0.90 & 0.90 & 0.90 & 6.0 \\
4 & & 3.00 & 0.75 & 0.75 & 0.75 & 0.75 & 6.0 \\
5 & & 3.60 & 0.60 & 0.60 & 0.60 & 0.60 & 6.0 \\
\hline
\end{tabular}




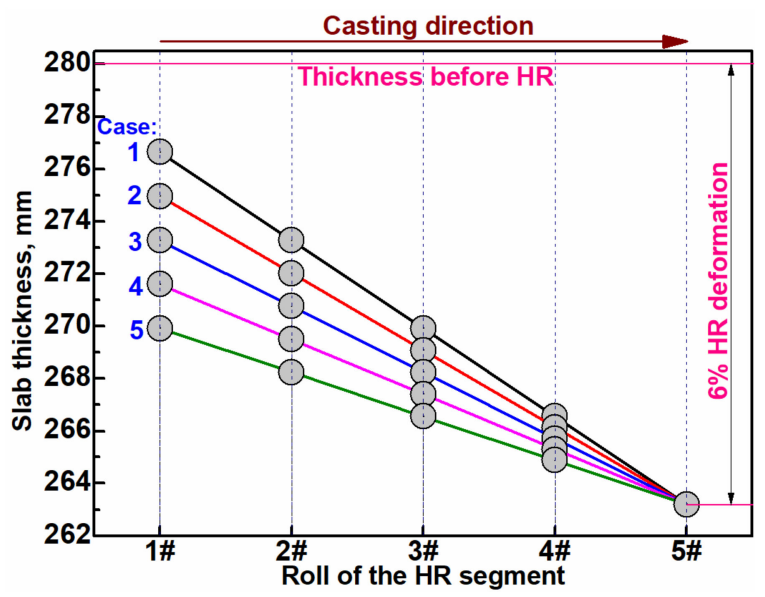

Figure 17. Variation of the slab thickness within the HR segment in Case 1 to 5 .

After $6 \%$ HR deformation implemented at the strand solidification end by the HR segment with the reduction mode of UHR (Case 1) and SPUHR (Case 2 to 5), the porosity deformation behaviors are presented in Figure 18. When compared with Case 1, porosity deformation degree along the slab thickness direction in Figure 18a and that along the slab width direction in Figure 18c increase while the porosity deformation degree along the casting direction in Figure $18 \mathrm{~b}$ decreases with HR deformation at Roller 1\# increased in Case 2 to 5 . This means that the porosity size after HR decreases along three axis directions with HR deformation at Roller 1\# increased.

Figure $18 \mathrm{~d}$ shows the porosity closure degree after HR in five cases. The porosity closure degree continuously increases with HR deformation at Roller 1\# increased, and, when compared with closure degree of $\mathrm{P}_{1 / 8}$ and $\mathrm{P}_{1 / 2}$ in Case 1, these two values, respectively, increase by $6.2 \%$ and $8.2 \%$ with HR deformation at Roller $1 \#$ increased to $3.6 \%$ in Case 5 . This indicates that the porosity can be improved more effectively by HR with the newly-proposed reduction mode of SPUHR and that the effect of SPUHR on improving the HR efficiency becomes more significant with the HR deformation at Roller $1 \#$ increased.

Figure 19 shows the equivalent stain at the slab center of $1 / 8$ width and $1 / 2$ width after HR in five cases. The continuously increasing trend of equivalent strain from Case 1 to 5 indicates that the HR deformation could transfer from the slab surface into its center more effectively with HR deformation as Roller 1\# increased. As a result, the porosity could be improved more effectively by HR with HR deformation as Roller 1\# increased, which explains the increasing trend of porosity closure degree in Figure $18 \mathrm{~d}$ and it proves the effect of SPUHR on improving HR efficiency.

During HR at the strand solidification end, HR efficiency continuously decreases from the entrance (Roller 1\#) to exit (Roller 5\#) of the HR segment due to the decrease of temperature difference. Therefore, with more HR deformation being concentrated at Roller $1 \#$ for the newly-proposed reduction mode of SPUHR, the final HR efficiency will be improved. However, in addition to temperature difference, another potential factor that may influence the HR efficiency is the distribution of HR deformation within the HR segment. Although the total HR deformation in Case 1 to 5 is equal, the slab deformation behavior at each roller changes with the change of HR deformation distribution within the HR segment, which may influence the final deformation behavior of the slab and its internal porosities after HR, even ignoring the variation of the slab temperature field within the HR segment. 


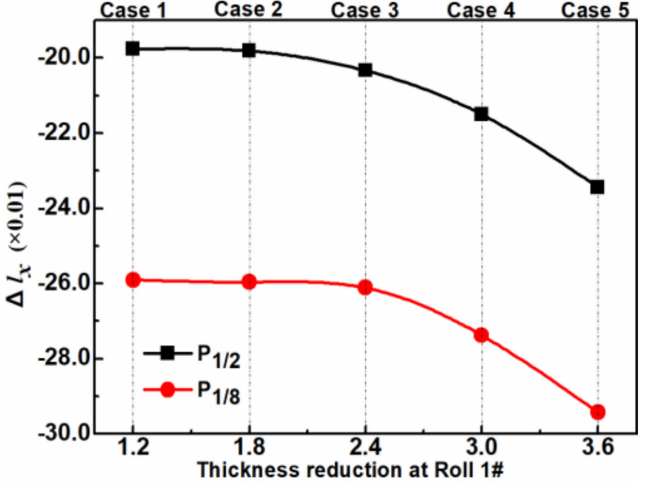

(a)

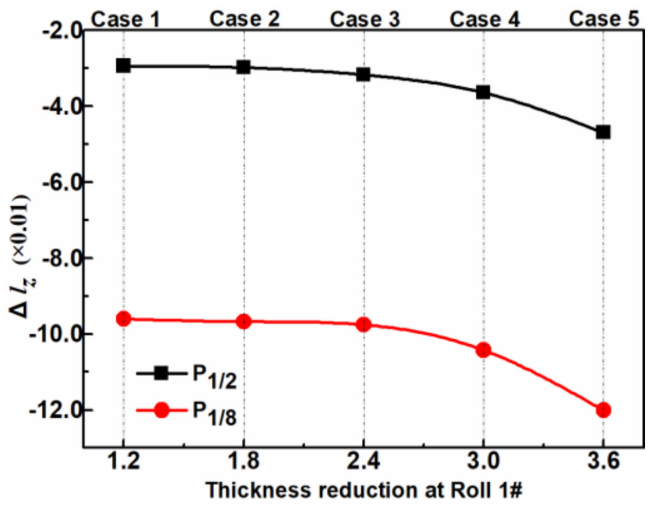

(c)

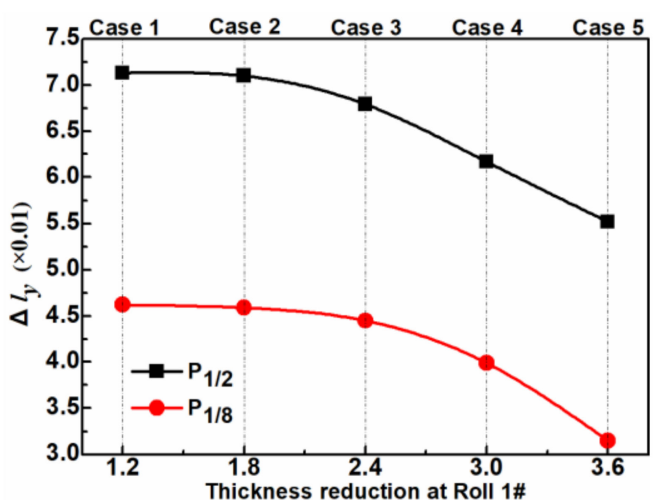

(b)

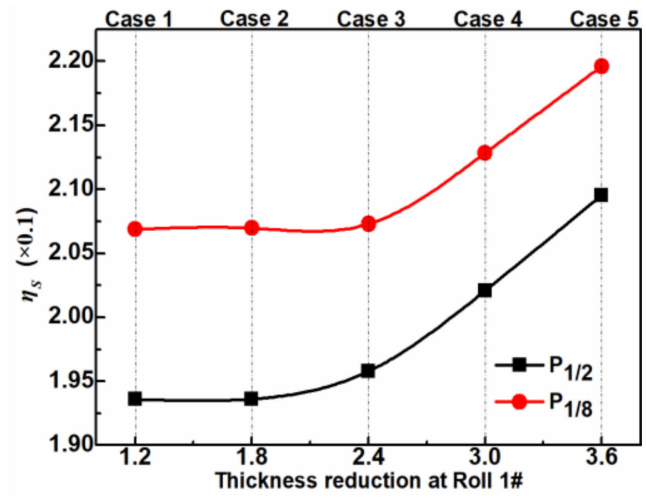

(d)

Figure 18. Porosity deformation degree along the (a) slab thickness direction, (b) casting direction, (c) slab width direction, and (d) the porosity closure degree after 6\% HR deformation in Case 1 to 5.

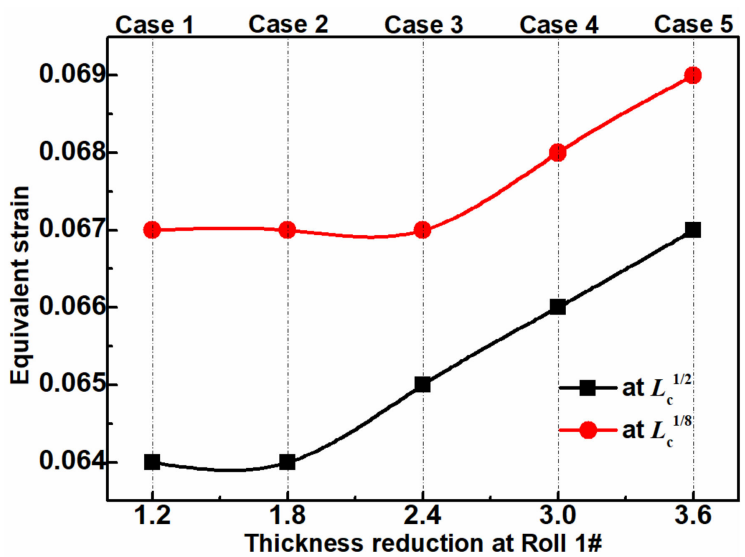

Figure 19. Equivalent strain at the slab center of $1 / 8$ width $\left(L_{\mathrm{c}}{ }^{1 / 8}\right)$ and $1 / 2$ width $\left(L_{\mathrm{c}}{ }^{1 / 2}\right)$ after $6 \% \mathrm{HR}$ deformation in Case 1 to 5.

To evaluate the influence of HR deformation distribution within the HR segment on the HR efficiency. The porosity closure degree after $6 \%$ HR deformation in Case 1 to 5 was calculated with the assumption that the slab temperature field during HR within the HR segment was fixed, and the calculated results are shown in Figure 20. It can be seen that, although the variation of the slab temperature field was neglected during $\mathrm{HR}$, the closure degree of $\mathrm{P}_{1 / 8}$ and $\mathrm{P}_{1 / 2}$ continuously increases by $5.9 \%$ and $5.2 \%$ from Case 1 to 5 . This proves that HR deformation distribution within the HR segment is another factor that influences the HR efficiency and that the HR efficiency will be improved more significantly with more HR deformation concentrated at Roller 1\#. 


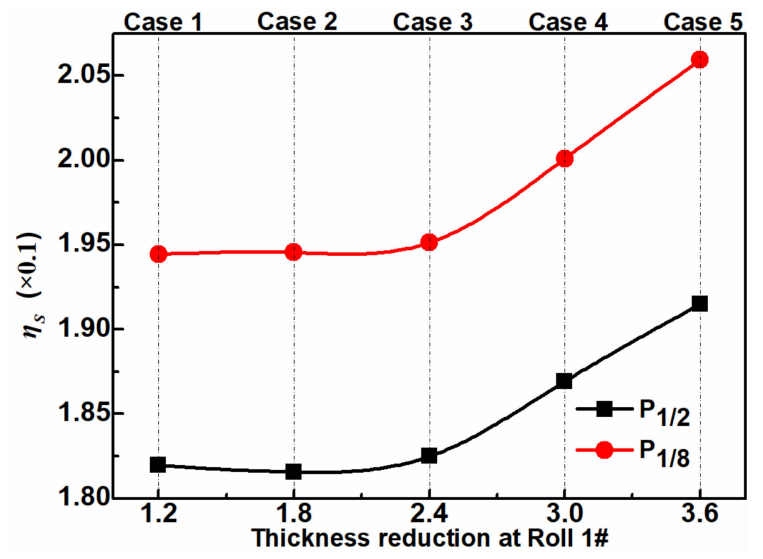

Figure 20. Porosity closure degree after HR in Case 1 to 5 ignoring the variation of the slab temperature field during HR.

\section{Prediction Model for Porosity Closure Behavior}

During HR, equivalent strain $\left(\varepsilon_{\text {eq }}\right)$ distribution of the casting steel could be easily determined by conducting thermal-mechanical analysis with a corresponding thermal-mechanical coupled model. This means that the process effect of HR on improving the internal porosities that were distributed at different locations of the casting steel can be directly evaluated with $\varepsilon_{\text {eq }}$ at the corresponding location if a quantitative relationship between the porosity deformation behavior and $\varepsilon_{\text {eq }}$ during HR could be established.

In order to derive the relationship between the porosity deformation behavior and $\varepsilon_{\text {eq }}$ for the wide-thick slab during $\mathrm{HR}$, the calculated closure degree $\left(\eta_{\mathrm{s}}\right)$ of $\mathrm{P}_{1 / 8}$ and $\mathrm{P}_{1 / 2}$ and the corresponding $\varepsilon_{\text {eq }}$ under different HR conditions in Section 3 are shown in Figure 21.

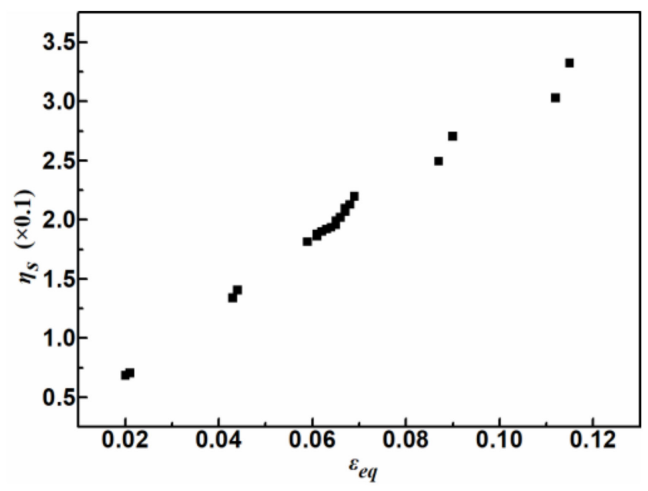

Figure 21. Relationship between the porosity closure degree $\left(\eta_{\mathrm{s}}\right)$ and the equivalent strain $\left(\varepsilon_{\mathrm{eq}}\right)$.

To quantitatively evaluate the correlation between $\eta_{\mathrm{s}}$ and $\varepsilon_{\text {eq }}$, the Pearson correlation coefficient [36] for the scattered data in Figure 21 was calculated with the following formula:

$$
r=\frac{\sum\left(X_{i}-\bar{X}\right)\left(Y_{i}-\bar{Y}\right)}{\left[\sum\left(X_{i}-\bar{X}\right)^{2} \sum\left(Y_{i}-\bar{Y}\right)^{2}\right]^{1 / 2}},
$$

where $r$ is the Pearson correlation coefficient; $X_{i}$ and $Y_{i}$ denote $\varepsilon_{\text {eq }}$ and the corresponding $\eta_{\mathrm{s}}$ for the scattered data in Figure 21; and, $\bar{X}$ and $\bar{Y}$ are, respectively, the mean value of $\varepsilon_{\mathrm{eq}}$ and $\eta_{\mathrm{s}}$ in Figure 21. The absolute value of $r$ ranges from 0 to 1 , and a larger absolute value of $r$ indicates a closer relationship between $X$ and $Y$.

The calculated result indicates that the $r$ value for the scattered data in Figure 21 reaches as high as 0.9938 , which proves that there exists a very close positive correlation between $\eta_{\mathrm{s}}$ and $\varepsilon_{\text {eq }}$ for the 
wide-thick slab during HR. In order to quantitatively describe the relationship between $\eta_{\mathrm{s}}$ and $\varepsilon_{\mathrm{eq}}$, polynomials with different orders were adopted to fit the scattered data in Figure 21 with the help of MATLAB. It was found that the quantitative relationship between $\eta_{\mathrm{s}}$ and $\varepsilon_{\mathrm{eq}}$ could be well described by a second order polynomial:

$$
\eta_{\mathrm{s}}=-5.23 \times \varepsilon_{\mathrm{eq}}^{2}+3.39 \times \varepsilon_{\mathrm{eq}}+0.12 \times 10^{-2},
$$

Comparison results between the original data in Figure 21 and the fitting results with Equation (9) are presented in Figure 22. It can be seen that the fitting results agree well with the original data. The adjusted $R$ square $\left(R^{2}\right)$ reaches 0.9921 , which proves the fitting accuracy.

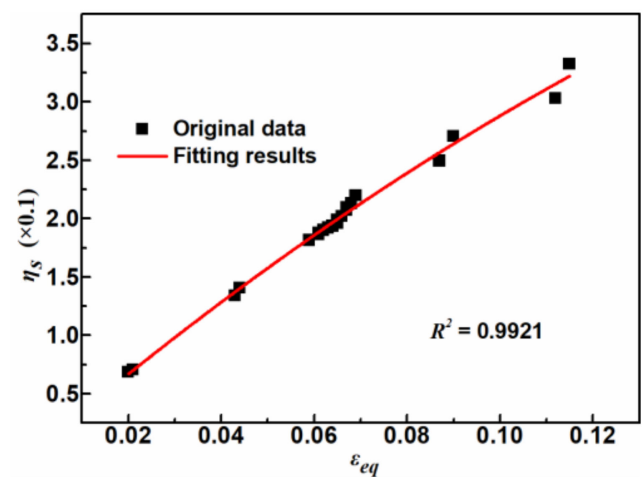

Figure 22. Comparison between the predicted and the fitting results for $\eta_{\mathrm{s}}$ and $\varepsilon_{\mathrm{eq}}$.

\section{Conclusions}

The deformation behavior of the internal porosities in wide-thick slab during HR was numerically investigated. Some main conclusions are summarized, as follows:

(1) After different HR deformation, the internal porosity size decreases along the slab thickness direction and the slab width direction and meanwhile increases along the casting direction, and the porosity deformation degree along the slab thickness direction $\left(\Delta l_{x}\right)$ is much larger than that along the casting direction $\left(\Delta l_{y}\right)$ and the slab width direction $\left(\Delta l_{z}\right)$. Due to the larger temperature difference at $1 / 8$ width during $H R$, the closure degree $\left(\eta_{s}\right)$ of $P_{1 / 8}$ is $9.7 \%$ larger than that of $P_{1 / 2}$ and it reaches 0.332 after $10 \%$ HR deformation.

(2) With HR start position moving away after the strand solidification end, $\Delta l_{x}$ and $\Delta l_{z}$ decrease, while $\Delta l_{y}$ increases. After $6 \%$ HR deformation within the HR segment, $\eta_{s}$ of $\mathrm{P}_{1 / 8}$ and $\mathrm{P}_{1 / 2}$ decrease by $9.3 \%$ and $6.3 \%$, respectively, with the HR starting position moving away by $3 \mathrm{~m}$ after the strand solidification end. Meanwhile, the required reduction force for the HR segment increases by $20 \%$. Therefore, HR efficiency on improving the internal porosities significantly decreases with the HR starting position moving away after the strand solidification end.

(3) When compared with the traditional reduction mode of UHR, the newly-proposed reduction mode of SPUHR could improve the HR efficiency. With more HR deformation being concentrated at entrance (Roller 1\#) of the HR segment for SPUHR, $\Delta l_{x}$ and $\Delta l_{z}$ increase, while $\Delta l_{y}$ decreases. $\eta_{\mathrm{s}}$ of $\mathrm{P}_{1 / 8}$ and $\mathrm{P}_{1 / 2}$ after total $6 \% \mathrm{HR}$ deformation, respectively, increases by $6.2 \%$ and $8.2 \%$ with HR deformation at Roller $1 \#$ increased from $1.2 \%$ to $3.6 \%$.

(4) A prediction model for the porosity closure behavior was derived based on the relationship between $\eta_{\mathrm{s}}$ and the corresponding equivalent strain $\left(\varepsilon_{\mathrm{eq}}\right)$, which can be expressed as:

$$
\eta_{\mathrm{s}}=-5.23 \times \varepsilon_{\mathrm{eq}}^{2}+3.39 \times \varepsilon_{\mathrm{eq}}+0.12 \times 10^{-2}
$$


Author Contributions: C.J. designed the paper and guided the development of the finite element models; M.Z. arranged the funding and revised the original manuscript; C.W. performed the numerical simulation and wrote the manuscript.

Funding: This research was funded by the National Natural Science Foundation of China No. 51474058 and U1708259, the Fundamental Research Funds for the Central Universities of China (N172504024).

Acknowledgments: Special thanks are due to the cooperating company for industrial trials and application.

Conflicts of Interest: The authors declare no conflict of interest.

\section{References}

1. Tanaka, M.; Ono, S.; Tsuneno, M.A. Numerical analysis on void crushing during side compression of round bar by flat dies. J. Jpn. Soc. Technol. Plast. 1987, 28, 238-244.

2. Nakasaki, M.; Takasu, I.; Utsunomiya, H. Application of hydrostatic integration parameter for free-forging and rolling. J. Mater. Process. Technol. 2006, 177, 521-524. [CrossRef]

3. Nalawade, R.S.; Patil, P.P.; Balachandran, G.; Balasubramanian, V. Void closure in a large cross section bars hot rolled from a low alloy steel ingot casting. Trans. Indian Inst. Met. 2016, 69, 1711-1721. [CrossRef]

4. Kakimoto, H.; Arikawa, T.; Takahashi, Y.; Tanaka, T.; Imaida, Y. Development of forging process design to close internal voids. J. Mater. Process. Technol. 2010, 210, 415-422. [CrossRef]

5. Wang, B.; Zhang, J.M.; Xiao, C.; Song, W.; Wang, S.X. Analysis of the evolution behavior of voids during the hot rolling process of medium plates. J. Mater. Process. Technol. 2015, 221, 121-127. [CrossRef]

6. Dudra, S.P.; Im, Y.T. Analysis of void closure in open-die forging. Int. J. Mach. Tools Manuf. 1990, 30, 65-75. [CrossRef]

7. Lee, Y.S.; Lee, S.U.; Van Tyne, C.J.; Joo, B.D. Internal void closure during the forging of large cast ingots using a simulation approach. J. Mater. Process. Technol. 2011, 211, 1136-1145. [CrossRef]

8. Park, J.J. Prediction of void closure in steel slabs by finite element analysis. Met. Mater. Int. 2013, 19, $259-265$. [CrossRef]

9. Park, J.J. Finite-Element analysis of cylindrical-void closure by flat-die forging. ISIJ Int. 2013, 53, 1420-1426. [CrossRef]

10. Chen, M.S.; Lin, Y.C. Numerical simulation and experimental verification of void evolution inside large forgings during hot working. Int. J. Plast. 2013, 49, 53-70. [CrossRef]

11. Ståhlberg, U.; Keife, H. A study of hole closure in hot rolling as influenced by forced cooling. J. Mater. Process. Technol. 1992, 30, 131-135. [CrossRef]

12. Verstam, H.; Jarl, M. FEM-simulation of drawing out in open die forging. Steel Res. Int. 2004, 75, 812-817. [CrossRef]

13. Li, G.S.; Yu, W.; Cai, Q.W. Investigation of the evolution of central defects in ultra-heavy plate rolled using gradient temperature process. Metall. Mater. Trans. B 2015, 46, 831-840.

14. Li, G.S.; Yu, W.; Cai, Q.W. Investigation of reduction pretreatment process for continuous casting. J. Mater. Process. Technol. 2016, 227, 41-48. [CrossRef]

15. Chun, M.S.; Van Tyne, C.J.; Moon, Y.H. FEM analysis of void closure behaviour during open die forging of rectangular billets. Steel Res. Int. 2006, 77, 116-121. [CrossRef]

16. Banaszek, G.; Stefanik, A. Theoretical and laboratory modelling of the closure of metallurgical defects during forming of a forging. J. Mater. Process. Technol. 2006, 177, 238-242. [CrossRef]

17. Chen, J.; Chandrashekhara, K.; Mahimkar, C.; Lekakh, S.N.; Richards, V.L. Study of void closure in hot radial forging process using 3D nonlinear finite element analysis. Int. J. Adv. Manuf. Technol. 2012, 62, 1001-1011. [CrossRef]

18. Park, C.Y.; Yang, D.Y. A study of void crushing in large forgings II. estimation of bonding efficiency by finite-element analysis. J. Mater. Process. Technol. 1997, 72, 32-41. [CrossRef]

19. Xu, Z.G.; Wang, X.H.; Jiang, M. Investigation on improvement of center porosity with heavy reduction in continuously cast thick slabs. Steel Res. Int. 2017, 88, 231-242. [CrossRef]

20. Zhao, X.K.; Zhang, J.M.; Lei, S.W.; Wang, Y.N. The position study of heavy reduction process for improving centerline segregation or porosity with extra-thickness slabs. Steel Res. Int. 2014, 85, 645-658. [CrossRef]

21. Zhao, X.K.; Zhang, J.M.; Lei, S.W.; Wang, Y.N. Finite-Element analysis of porosity closure by heavy reduction process combined with ultra-heavy plates rolling. Steel Res. Int. 2014, 85, 1533-1543. [CrossRef] 
22. Ji, C.; Luo, S.; Zhu, M.Y. Analysis and application of soft reduction amount for bloom continuous casting process. ISIJ Int. 2014, 54, 504-510. [CrossRef]

23. Luo, S.; Zhu, M.Y.; Ji, C. Theoretical model for determining optimum soft reduction zone of continuous casting steel. Ironmak. Steelmak. 2014, 41, 233-240. [CrossRef]

24. Nabeshima, S.; Nakato, H.; Fujii, T.; Kushida, K.; Mizota, H. Control of centerline segregation in continuously cast blooms by continuous forging process. ISIJ Int. 1995, 35, 673-679. [CrossRef]

25. Kojima, S.; Imai, T.; Mizota, H.; Fujimura, T.; Matsukawa, T. Improvement of centerline segregation in continuously cast strand by continuous forging process. Tetsu Hagane 1992, 78, 1794-1801. [CrossRef]

26. Hiraki, S.; Yamanaka, A.; Shirai, Y.; Satou, Y.; Kumakura, S. Development of new continuous casting technology (PCCS) for very thick plate. Mater. Jpn. 2009, 48, 20-22. [CrossRef]

27. Kawamoto, M. Recent development of steelmaking process in Sumitomo Metals. J. Iron Steel Res. Int. 2011, 18, $28-35$.

28. Ji, C.; Wu, C.H.; Zhu, M.Y. Thermo-mechanical behavior of the continuous casting bloom in the heavy reduction process. JOM 2016, 68, 3107-3115. [CrossRef]

29. Zhao, J.P.; Liu, L.; Wang, W.W.; Lu, H. Effects of heavy reduction technology on internal quality of continuous casting bloom. Ironmak. Steelmak. 2017. [CrossRef]

30. Dong, Q.P.; Zhang, J.M.; Wang, B.; Zhao, X.K. Shrinkage porosity and its alleviation by heavy reduction in continuously cast strand. J. Mater. Process. Technol. 2016, 238, 81-88. [CrossRef]

31. Wang, H.M.; Li, G.R.; Lei, Y.C.; Zhao, Y.T.; Dai, Q.X.; Wang, J.J. Mathematical heat transfer model research for the improvement of continuous casting slab temperature. ISIJ Int. 2005, 45, 1291-1296. [CrossRef]

32. Li, C.; Thomas, B.G. Thermomechanical finite-element model of shell behavior in continuous casting of steel. Metall. Mater. Trans. B 2004, 35B, 1151-1172. [CrossRef]

33. Ji, C.; Luo, S.; Zhu, M.Y.; Sahai, Y. Uneven solidification during wide-thick slab continuous casting process and its influence on soft reduction zone. ISIJ Int. 2014, 54, 103-111. [CrossRef]

34. Wu, C.H.; Ji, C.; Zhu, M.Y. Analysis of the thermal contraction of wide-thick continuously cast slab and the weighted average method to design a roll gap. Steel Res. Int. 2017, 88, 1600514. [CrossRef]

35. Ji, C.; Wang, Z.L.; Wu, C.H.; Zhu, M.Y. Constitutive modeling of the flow stress of GCr15 continuous casting bloom in the heavy reduction process. Metall. Mater. Trans. B 2018, 49, 767-782. [CrossRef]

36. Rodgers, J.L.; Nicewander, W.A. Thirteen ways to look at the correlation coefficient. Am. Stat. 1988, 42, 59-66. [CrossRef]

(C) 2019 by the authors. Licensee MDPI, Basel, Switzerland. This article is an open access article distributed under the terms and conditions of the Creative Commons Attribution (CC BY) license (http:/ / creativecommons.org/licenses/by/4.0/). 